\title{
Analgesia and curative effect of pamidronate disodium combined with chemotherapy on elderly patients with advanced metastatic bone cancer
}

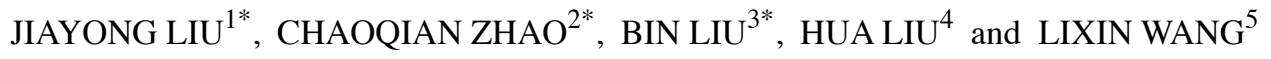 \\ ${ }^{1}$ Key Laboratory of Carcinogenesis and Translational Research (Ministry of Education/Beijing), \\ Department of Bone and Soft Tissue Tumor, Peking University Cancer Hospital and Institute, Beijing 100142; \\ ${ }^{2}$ Department of Oncology, Zhuzhou Central Hospital, Zhuzhou, Hunan 412007; ${ }^{3}$ Department of Oncology, \\ The Second Hospital of Xiangya, Central South University, Changsha, Hunan 410011; \\ ${ }^{4}$ Department of Respiratory and Critical Care Medicine, Affiliated Hospital of Nantong University, \\ Nantong, Jiangsu 226001; ${ }^{5}$ Department of Integrated TCM and Western Medicine, \\ Shanghai Pulmonary Hospital Affiliated to Tongji University, Shanghai 200043, P.R. China
}

Received January 24, 2019; Accepted May 6, 2019

DOI: $10.3892 / \mathrm{ol} .2019 .10340$

\begin{abstract}
The curative effect and adverse reactions of pamidronate disodium in elderly patients with advanced metastatic bone cancer were evaluated. A total of 160 elderly patients with advanced metastatic bone cancer admitted to Affiliated Hospital of Nantong University from February 2012 to January 2015, were divided into the chemotherapy group $(n=60)$ that received routine therapy and the pamidronate disodium group $(\mathrm{n}=100)$ that received pamidronate disodium therapy based on the chemotherapy. Pain relief, analgesic time, analgesic duration and side effects were compared between the two groups after treatment. The effect of pain relief in the pamidronate disodium group was significantly higher than that in the chemotherapy group $(\mathrm{P}<0.001)$. The total effective rate of the pamidronate disodium group was significantly higher than that of the chemotherapy group $(\mathrm{P}<0.001)$. The analgesic onset time in the pamidronate disodium group was earlier than in the chemotherapy group $(\mathrm{P}<0.001)$. The analgesic duration in the pamidronate disodium group was longer than that in the chemotherapy group $(\mathrm{P}<0.001)$. The incidence of adverse reactions and complications after treatment in the
\end{abstract}

Correspondence to: Dr Hua Liu, Department of Respiratory and Critical Care Medicine, Affiliated Hospital of Nantong University, 20 Xisi road, Nantong, Jiangsu 226001, P.R. China

E-mail: hbncb2@163.com; hbncb2@163.com

Dr Lixin Wang, Department of Integrated TCM and Western Medicine, Shanghai Pulmonary Hospital Affiliated to Tongji University, 507 Zhengmin road, Shanghai 200043, P.R. China

E-mail:wlx1126@hotmail.com

${ }^{*}$ Contributed equally

Key words: pamidronate disodium, bone metastasis, analgesia, curative effect, elderly patients with advanced cancer pamidronate disodium group was significantly less than that in the chemotherapy group $(\mathrm{P}<0.001)$. The results indicated that pamidronate disodium is effective in the treatment of elderly patients with advanced metastatic bone cancer and patients are less prone to adverse reactions, complications and pain, which is worthy of clinical application.

\section{Introduction}

Bone metastasis, a common complication of solid tumors such as advanced breast cancer, prostate cancer and lung cancer, has high incidence (1-3). Patients with advanced tumors suffer from bone pain and fracture due to the deterioration of tumors and bone metastases, causing bone cell absorption and osteolysis, or even bone destruction $(4,5)$. Patients with bone metastases endure severe pain resulting in low quality of life and poor mental health, as well as loss of confidence in life (6). Morphine is a routine analgesic in the late stage of clinical treatment but with poor effect for patients with bone metastasis because of short onset time and side effects (7). Therefore, the effective analgesic treatment for patients with bone metastases is currently a hot topic in clinical research (8).

Chemoradiotherapy, radionuclide, analgesic and bisphosphonate therapies are currently important methods for bone metastases from malignant tumors (9-11). In the treatment and prevention of complications of bone metastasis from malignant tumors, some studies have indicated that bisphosphonates are effective in alleviating pathological bone pain of patients (12). Bisphosphonates play an important role in reversing bone destruction such as bone cell absorption and osteolysis, especially pamidronate disodium, one of the bisphosphonates, which was effective in inhibiting bone resorption and osteolytic bone metastasis (13). Zoledronic acid and pamidronate disodium are widely-used bisphosphonates clinically $(14,15)$. Therefore, this study aimed to analyze the curative effect and side effects of pamidronate disodium in the treatment of elderly patients with advanced metastatic bone cancer. 
Table I. General data of the two groups [n (\%)].

\begin{tabular}{|c|c|c|c|c|}
\hline Variables & Pamidronate disodium group $(n=100)$ & Chemotherapy group $(\mathrm{n}=60)$ & $t / \chi^{2}$ & P-value \\
\hline Age (years) & $53.67 \pm 4.81$ & $53.15 \pm 4.93$ & 0.656 & 0.513 \\
\hline Sex & & & 0.220 & 0.639 \\
\hline Men & $63(63.00)$ & $40(66.67)$ & & \\
\hline Women & $37(37.00)$ & $20(33.33)$ & & \\
\hline $\operatorname{BMI}\left(\mathrm{kg} / \mathrm{m}^{2}\right)$ & $18.93 \pm 4.12$ & $18.42 \pm 3.84$ & 0.778 & 0.438 \\
\hline \multicolumn{5}{|l|}{ Types of cancer } \\
\hline Esophageal carcinoma & $15(15.00)$ & $7(11.67)$ & 0.351 & 0.553 \\
\hline Lung cancer & $24(24.00)$ & $16(26.67)$ & 0.142 & 0.706 \\
\hline Cervical cancer & $20(20.00)$ & $12(20.00)$ & 0.000 & 1.000 \\
\hline Prostate cancer & $13(13.00)$ & $5(8.33)$ & 0.818 & 0.366 \\
\hline Nasopharyngeal cancer & $28(28.00)$ & $20(33.33)$ & 0.508 & 0.476 \\
\hline Number of bone metastases & & & 0.886 & 0.347 \\
\hline 1 & $68(68.00)$ & $45(75.00)$ & & \\
\hline$>1$ & $32(32.00)$ & $15(25.00)$ & & \\
\hline
\end{tabular}

BMI, body mass index.

\section{Patients and methods}

Patients data. A total of 160 elderly patients with advanced metastatic bone cancer admitted to Affiliated Hospital of Nantong University (Nantong, China) from February 2012 to January 2015 were divided into in the chemotherapy group $(n=60)$ that received routine therapy and the pamidronate disodium group $(n=100)$ that received pamidronate disodium therapy based on the chemotherapy. Patients in the chemotherapy group ranged in age from 46 to 72 years, with an average age of $53.15 \pm 4.93$ years. Patients in the pamidronate disodium group ranged in age from 47 to 69 years, with an average age of $53.67 \pm 4.81$ years. Inclusion criteria were as follows: i) patients who met the international diagnostic criteria for malignant tumors and were diagnosed as bone metastases through pathological examination and medical imaging technology (16); and ii) patients who did not have surgical treatment. Exclusion criteria were as follows: i) presence of neurological diseases, liver and renal dysfunction and organic diseases, severe complications, failure of chemotherapy and follow-up.

The study was approved by the Ethics Committee of Affiliated Hospital of Nantong University. Signed informed consents were obtained from the patients or guardians.

Methods. Treatment methods: Both groups received chemotherapy according to the clinical medication guidelines for primary tumors. Based on the chemotherapy group, patients in the pamidronate disodium group were treated with $45 \mathrm{mg}$ pamidronate disodium (SFDA approval no. H19980200; Shenzhen Neptunus Pharmaceutical Co., Ltd.) and $500 \mathrm{ml}$ sodium chloride solution with $0.9 \%$ concentration twice a week, once a day, four weeks a course and three courses for the treatment. Liver and kidney functions were measured each week.
Evaluation of curative effect. Criteria of pain relief effect and bone lesions were as follows: according to Verbal Rating Scale (VRS) (17), pain is divided into grade 0 to III: the higher the grade, the more severe the pain. The pain grading standard is as follows: downregulation by one level indicating effectiveness, by two levels indicating marked effectiveness, upregulation or unchanged indicating ineffectiveness. The total effective rate of pain relief $=$ (marked effectiveness)/effectiveness + effectiveness/total number of cases $\times 100 \%$. Evaluation of curative effect of bone lesions: $\mathrm{CR}$ indicates the disappearance of bone lesions for 4 weeks or less. PR indicates that the area of diseased tissue reduced and the density of calcification of bone lesions was 4 weeks or less. NC indicates no change in the area of bone lesions. PD indicates that new bone lesions or the area of original bone lesions increased. The total effective rate of bone lesions $=(\mathrm{CR}+\mathrm{PR}) /$ total number of cases $\times 100 \%$.

Statistical analysis. SPSS19.0 (Bizinsight Information Technology Co., Ltd.) software was used for statistical analysis. The enumeration data were expressed as the number of cases/percentage [n (\%)] and tested by $\chi^{2}$ test. The measurement data were expressed as mean \pm standard deviation and tested by independent sample t-test at the same time-point. $\mathrm{P}<0.05$ was considered to indicate a statistically significant difference.

\section{Results}

General data of patients. There was no significant difference in general data between the two groups ( $\mathrm{P}>0.05$; Table I).

Comparison of pain relief between the two groups after treatment. The pain relief effect in the pamidronate disodium group was as follows: patients with marked effectiveness: 39 cases, 
Table II. Comparison of pain relief between the two groups after treatment [n (\%)].

\begin{tabular}{|c|c|c|c|c|c|}
\hline Groups & $\mathrm{n}$ & $\begin{array}{c}\text { No. of } \\
\text { marked effectiveness }\end{array}$ & $\begin{array}{c}\text { No. of } \\
\text { effectiveness }\end{array}$ & $\begin{array}{c}\text { No. of } \\
\text { ineffectiveness or deterioration }\end{array}$ & $\begin{array}{l}\text { Total } \\
\text { effective rate }\end{array}$ \\
\hline Pamidronate disodium & 100 & $39(39.00)$ & $46(46.00)$ & $15(15.00)$ & $85(85.00)$ \\
\hline Chemotherapy & 60 & $21(35.00)$ & $12(20.00)$ & $27(45.00)$ & $33(55.00)$ \\
\hline$\chi^{2}$ & & - & - & - & 17.430 \\
\hline $\mathrm{P}$-value & & - & - & - & $<0.001$ \\
\hline
\end{tabular}

Table III. Comparison of the curative effect of bone metastases between the two groups after treatment [n (\%)].

\begin{tabular}{lcccccc}
\hline Groups & $\mathrm{n}$ & $\mathrm{CR}$ & $\mathrm{PR}$ & $\mathrm{SD}$ & PD & Total effective rate \\
\hline Pamidronate disodium & 100 & $35(35.00)$ & $19(19.00)$ & $24(24.00)$ & $22(22.00)$ & $54(54.00)$ \\
Chemotherapy & 60 & $11(18.33)$ & $1(1.67)$ & $28(46.67)$ & $20(33.33)$ & $12(20.00)$ \\
$\chi^{2}$ & & - & - & - & - & - \\
P-value & & - & - & - & $<.360$ & $<01$ \\
\hline
\end{tabular}

Table IV. Comparison of analgesic time and duration (h) between the two groups.

\begin{tabular}{lrrr}
\hline Groups & Pamidronate disodium group & Chemotherapy group & $\mathrm{t}$ \\
\hline Analgesic onset time & $4.59 \pm 0.74$ & $8.12 \pm 0.62$ & 30.990 \\
Analgesic duration & $21.01 \pm 2.45$ & $12.45 \pm 3.15$ & $<0.001$ \\
\hline
\end{tabular}

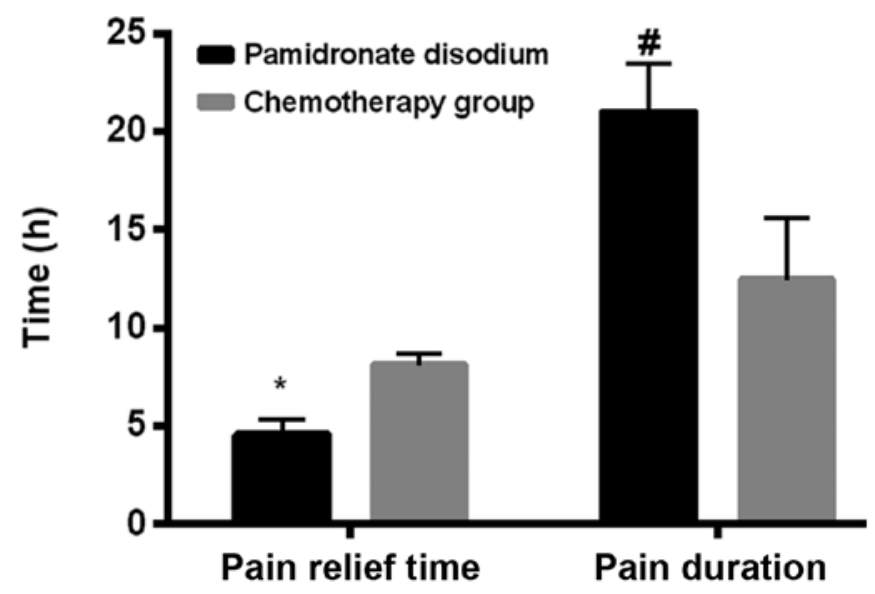

Figure 1. Comparison of analgesic time and duration between the two groups. The analgesic onset time of the pamidronate disodium group was earlier than that of the chemotherapy group $\left({ }^{*} \mathrm{P}<0.001\right)$; The duration of analgesic time in the pamidronate disodium group was longer than that in the chemotherapy group $(" \mathrm{P}<0.001)$.

effectiveness: 46 cases, ineffectiveness: 15 cases. While in the chemotherapy group, patients with marked effectiveness: 21 cases, effectiveness: 12 cases, ineffectiveness: 27 cases. The total effective rate of pain relief in the pamidronate disodium group was $85 \%$, higher than that in the chemotherapy group $(\mathrm{P}<0.001$; Table II).
Comparison of curative effect of bone metastases between the two groups after treatment. The curative effect of bone metastases in the pamidronate disodium group was: CR cases: 35, PR cases: 19, SD cases: 24, PD cases: 22; while in the chemotherapy group was: CR cases: 11 , PR cases: 1, SD cases: 28 , PD cases: 20. The total effective rate of pain relief in the pamidronate disodium group was $54 \%$, higher than that in the chemotherapy group $(\mathrm{P}<0.001$; Table III).

Analysis of analgesic time and duration between the two groups. The analgesic onset time in the pamidronate disodium group was $4.59 \pm 0.74 \mathrm{~h}$, while the chemotherapy group was $8.12 \pm 0.62 \mathrm{~h}$. Compared between the two groups, the onset time in the pamidronate disodium group was earlier than that in the chemotherapy group $(\mathrm{P}<0.001)$. The duration of analgesic time in the pamidronate disodium group was $21.01 \pm 2.45 \mathrm{~h}$, while the chemotherapy group was $12.45 \pm 3.15 \mathrm{~h}$. The duration of analgesic time in the pamidronate disodium group was longer than that in the chemotherapy group ( $\mathrm{P}<0.001$; Table IV and Fig. 1).

Analysis of side effects between the two groups. The total incidence of adverse reactions and complications, such as hypercalcemia, oesophagus damage, renal dysfunction, nausea and vomiting, body aches and chills in the pamidronate disodium group was $28.00 \%$ after treatment, which was significantly lower than that in the chemotherapy group (63.33\%) $(\mathrm{P}<0.001$; Table V). 
Table V. Comparison of adverse reactions and complications between the two groups [n (\%)].

\begin{tabular}{|c|c|c|c|c|c|c|c|}
\hline Groups & Hypercalcemia & $\begin{array}{c}\text { Oesophagus } \\
\text { damage }\end{array}$ & $\begin{array}{c}\text { Renal } \\
\text { dysfunction }\end{array}$ & $\begin{array}{c}\text { Nausea } \\
\text { and vomiting }\end{array}$ & Body aches & Body chills & Total \\
\hline Pamidronate disodium & $2(2.00)$ & $4(4.00)$ & $12(12.00)$ & $4(4.00)$ & $3(3.00)$ & $3(3.00)$ & $28(28.00)$ \\
\hline Chemotherapy & $2(3.33)$ & $5(8.33)$ & $13(21.67)$ & $6(10.00)$ & $6(10.00)$ & $6(10.00)$ & $38(63.33)$ \\
\hline$\chi^{2}$ & - & - & - & - & - & - & 19.320 \\
\hline P-value & - & - & - & - & - & - & $<0.001$ \\
\hline
\end{tabular}

\section{Discussion}

In this study, the general data of elderly patients with advanced metastatic bone cancer in the two groups were comparable according to different treatment methods. Differences in pain relief effect in bone metastasis lesions, analgesic onset time and duration, adverse reactions were compared between the two groups after treatment. The total effective rate of pain relief in the pamidronate disodium group was $85 \%$, higher than that in the chemotherapy group. The total effective rate of bone lesion metastases in the pamidronate disodium group was $54 \%$, higher than that of the chemotherapy group. Pathological fracture or complications caused by advanced metastatic bone cancer have a serious impact on physiology and psychology of patients (18). At present, great importance has been attached to studies on patients with bone metastases. A large number of studies have indicated that different treatment methods had different effects on pain in patients with metastatic bone cancer (19).

Chemotherapy is a common treatment for patients with metastatic bone cancer, but it cannot alleviate the pathological pain caused by bone metastasis (20). Pamidronate disodium, a second-generation bisphosphonate drug, is a bone resorption inhibitor (21). Relevant studies have demonstrated that pamidronate disodium was effective in cancer-related hypercalcemia and bone pain caused by malignant tumors (22). Therefore, it is likely that pamidronate disodium therapy based on chemotherapy is more effective than conventional chemotherapy in relieving bone pain. Goblirsch et al suggested that bisphosphonates showed a good effect in the treatment of patients with bone metastases of malignant tumors (23), which is similar to the results of the study. The analgesic onset time and duration of the pamidronate disodium and the chemotherapy groups were analyzed. It was found that the analgesic onset time of the pamidronate disodium group was earlier than that of the chemotherapy group while the duration of analgesic time in the pamidronate disodium group was longer than that in the chemotherapy group, indicating statistical differences.

A large number of studies have shown that pamidronate disodium and other bisphosphonates could shorten analgesic onset time and increase duration of analgesic effect, which is of great significance for improving the curative effect and quality of life (24). According to adverse reactions of the two groups, the total incidence of adverse reactions, such as hypercalcemia, oesophagus damage, renal dysfunction, nausea and vomiting, body aches and chills, in the pamidronate disodium group was significantly lower than that in the chemotherapy group after treatment. Some studies indicated that complications such as bone pain, pathological fracture and hypercalcemia caused by bone metastasis of malignant tumors not only had a serious impact on quality of life of patients, but also caused death of patients with malignant tumors (25). Nausea and vomiting, body aches and chills are common adverse reactions in chemotherapy (26). Wong and Wiffen suggested that bisphosphonates in the treatment of bone metastasis of malignant tumors enhanced the prevention of complications and adverse reactions, and reduced the incidence of adverse reactions (27). Therefore, pamidronate disodium therapy based on chemotherapy is more effective than the conventional chemotherapy in preventing the complications and adverse reactions.

In conclusion, pamidronate disodium therapy based on chemotherapy can improve the analgesic effect and curative effect and prevent complications and adverse side effects of elderly patients with advanced metastatic bone cancer, which is worthy of clinical promotion.

\section{Acknowledgements}

Not applicable.

\section{Funding}

This study was supported by National Natural Science Foundation (8157937).

\section{Availability of data and materials}

The datasets used and/or analyzed during the present study are available from the corresponding author on reasonable request.

\section{Authors' contributions}

JL, CZ and BL led the conception and design of the study. JL and $\mathrm{CZ}$ were responsible for evaluation of curative effect. BL and LW were responsible for the general data collection and analysis. HL and LW were in charge of interpreting the data and drafting the manuscript. $\mathrm{CZ}$ and $\mathrm{BL}$ made revision from critical perspective for important intellectual content. The final version was read and approved by all the authors.

\section{Ethics approval and consent to participate}

The study was approved by the Ethics Committee of Affiliated Hospital of Nantong University (Nantong, China). 
Signed informed consents were obtained from the patients or guardians.

\section{Patient consent for publication}

Not applicable.

\section{Competing interests}

The authors declare that they have no competing interests.

\section{References}

1. Masuda T, Endo M, Yamamoto Y, Odagiri H, Kadomatsu T, Nakamura T, Tanoue H, Ito H, Yugami M, Miyata K, et al: ANGPTL2 increases bone metastasis of breast cancer cells through enhancing CXCR4 signaling. Sci Rep 5: 9170, 2015.

2. Siu MK, Tsai YC, Chang YS, Yin JJ, Suau F, Chen WY and Liu YN: Transforming growth factor- $\beta$ promotes prostate bone metastasis through induction of microRNA-96 and activation of the mTOR pathway. Oncogene 34: 4767-4776, 2015.

3. Yang X, Li L, Huang Q, Xu W, Cai X, Zhang J, Yan W, Song D, Liu T, Zhou W, et al: Wnt signaling through Snaill and Zeb1 regulates bone metastasis in lung cancer. Am J Cancer Res 5 : 748-755, 2015

4. Croucher PI, McDonald MM and Martin TJ: Bone metastasis: the importance of the neighbourhood. Nat Rev Cancer 16: 373-386, 2016.

5. Colden M, Dar AA, Saini S, Dahiya PV, Shahryari V, Yamamura S, Tanaka Y, Stein G, Dahiya R and Majid S: MicroRNA-466 inhibits tumor growth and bone metastasis in prostate cancer by direct regulation of osteogenic transcription factor RUNX2. Cell Death Dis 8: e2572, 2017.

6. Westhoff PG, de Graeff A, Monninkhof EM, Berveling MJ, van Vulpen M, Leer JWH, Marijnen CAM, Reyners AKL and van der Linden YM; Dutch Bone Metastasis Study Group: Screening for psychological distress before radiotherapy for painful bone metastases may be useful to identify patients with high levels of distress. Acta Oncol 56: 1720-1727, 2017.

7. von Moos R, Body JJ, Egerdie B, Stopeck A, Brown J, Fallowfield L, Patrick DL, Cleeland C, Damyanov D, Palazzo FS, et al: Pain and analgesic use associated with skeletal-related events in patients with advanced cancer and bone metastases. Support Care Cancer 24: 1327-1337, 2016.

8. Porta-Sales J, Garzón-Rodríguez C, Llorens-Torromé S, Brunelli C, Pigni A and Caraceni A: Evidence on the analgesic role of bisphosphonates and denosumab in the treatment of pain due to bone metastases: a systematic review within the European Association for Palliative Care guidelines project. Palliat Med 31: $5-25,2017$.

9. Inoue M, Otsuka $\mathrm{K}$ and Shibata $\mathrm{H}$ : Circulating tumor cell count as a biomarker of a specific gastric cancer subgroup characterized by bone metastasis and/or disseminated intravascular coagulation - an early indicator of chemotherapeutic response. Oncol Lett 11: 1294-1298, 2016.

10. Alavi M, Omidvari S, Mehdizadeh A, Jalilian AR and Bahrami-Samani A: Metastatic bone pain palliation using (177) Lu-ethylenediaminetetramethylene phosphonic acid. World J Nucl Med 14: 109-115, 2015.

11. Fischer $\mathrm{M}$ and Biersack HJ: Radionuclide therapy of malignant bone lesions. Eur J Nucl Med Mol Imaging 44: 728-729, 2017.

12. Lebret T, Casas A, Cavo M, Woll PJ, Deleplace C, Kennedy C, Schoen P and Jackisch C: The use of bisphosphonates in the management of bone involvement from solid tumours and haematological malignancies - a European survey. Eur J Cancer Care (Engl) 26: 26, 2017.
13. Singh T, Kaur V, Kumar M, Kaur P, Murthy RS and Rawal RK The critical role of bisphosphonates to target bone cancer metastasis: an overview. J Drug Target 23: 1-15, 2015.

14. Shapiro CL, Moriarty JP, Dusetzina S, Himelstein AL, Foster JC, Grubbs SS, Novotny PJ and Borah BJ: Cost-effectiveness analysis of monthly zoledronic acid, zoledronic acid every 3 months, and monthly denosumab in women with breast cancer and skeletal metastases: CALGB 70604 (Alliance). J Clin Oncol 35: 3949-3955, 2017.

15. Glover D, Lipton A, Keller A, Miller AA, Browning S, Fram RJ, George S, Zelenakas K, Macerata RS and Seaman JJ: Intravenous pamidronate disodium treatment of bone metastases in patients with breast cancer. A dose-seeking study. Cancer 74: 2949-2955, 1994.

16. Even-Sapir E: Imaging of malignant bone involvement by morphologic, scintigraphic, and hybrid modalities. J Nucl Med 46: 1356-1367, 2005.

17. Hjermstad MJ, Fayers PM, Haugen DF, Caraceni A, Hanks GW, Loge JH, Fainsinger R, Aass N and Kaasa S; European Palliative Care Research Collaborative (EPCRC): Studies comparing numerical rating scales, verbal rating scales, and visual analogue scales for assessment of pain intensity in adults: a systematic literature review. J Pain Symptom Manage 41: 1073-1093, 2011.

18. Stopeck AT, Lipton A, Body JJ, Steger GG, Tonkin K, de Boer RH, Lichinitser M, Fujiwara Y, Yardley DA, Viniegra M, et al: Denosumab compared with zoledronic acid for the treatment of bone metastases in patients with advanced breast cancer: a randomized, double-blind study. J Clin Oncol 28: 5132-5139, 2010.

19. Costa L and Major PP: Effect of bisphosphonates on pain and quality of life in patients with bone metastases. Nat Clin Pract Oncol 6: 163-174, 2009.

20. Body JJ, Casimiro S and Costa L: Targeting bone metastases in prostate cancer: Improving clinical outcome. Nat Rev Urol 12: 340-356, 2015

21. Xu Y, Sun J, Yang X, Yu Y, Mai H and Li Z: Pamidronate disodium leads to bone necrosis via suppression of $\mathrm{Wnt} / \beta$-catenin signaling in human bone marrow mesenchymal stem cells in vitro. J Oral Maxillofac Surg 75: 2135-2143, 2017

22. Li P and Hu Y: 'Turn-Off' fluorescent sensor for pamidronate disodium and zoledronic acid based on newly synthesized carbon dots from black tea. J Anal Methods Chem 2018: 3631249, 2018.

23. Goblirsch MJ, Zwolak PP and Clohisy DR: Biology of bone cancer pain. Clin Cancer Res 12: 6231s-6235s, 2006.

24. Lipton A, Small E, Saad F, Gleason D, Gordon D, Smith M, Rosen L, Kowalski MO, Reitsma D and Seaman J: The new bisphosphonate, Zometa (zoledronic acid), decreases skeletal complications in both osteolytic and osteoblastic lesions: a comparison to pamidronate. Cancer Invest 20 (Suppl 2): 45-54, 2002.

25. Diel IJ, Body JJ, Stopeck AT, Vadhan-Raj S, Spencer A, Steger G, von Moos R, Goldwasser F, Feng A and Braun A: The role of denosumab in the prevention of hypercalcaemia of malignancy in cancer patients with metastatic bone disease. Eur J Cancer 51: 1467-1475, 2015.

26. Wang S, Liu F, Zhu J, Chen P, Liu H, Liu Q and Han J: DNA repair genes ERCC1 and BRCA1 expression in non-small cell lung cancer chemotherapy drug resistance. Med Sci Monit 22: 1999-2005, 2016.

27. Wong R and Wiffen PJ: Bisphosphonates for the relief of pain secondary to bone metastases. Cochrane Database Syst Rev 2: CD002068, 2002.

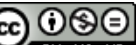

This work is licensed under a Creative Commons

Attribution-NonCommercial-NoDerivatives 4.0 International (CC BY-NC-ND 4.0) License. 